\title{
Las partículas similares a virus (VLPs, virus-likeparticles) y su empleo en vacunología
}

\section{Virus-like particles and its applications in vaccinology}

REVIEW

\section{Agustín Francisco De Ganzó}

Universidad Nacional de Quilmes, Departamento de Ciencia y Tecnología, Instituto de Microbiología Básica y Aplicada, Laboratorio de Ingeniería Genética y Biología Celular y Molecular, Área de Virosis Emergentes y Zoonóticas, Argentina

Contacto: agustindeganzo@gmail.com

\section{Cristina Silvia Borio}

Universidad Nacional de Quilmes, Departamento de Ciencia y Tecnología, Área de Virosis Emergentes y Zoonóticas, Laboratorio de Ingeniería Genética y Biología Celular y Molecular, Instituto de Microbiología Básica y Aplicada, Argentina.

Contacto: cristinaborio@gmail.com

\section{Mercedes Pastorini}

Universidad Nacional de Quilmes, Departamento de Ciencia y Tecnología, Área de Virosis Emergentes y Zoonóticas, Laboratorio de Ingeniería Genética y Biología Celular y Molecular, Instituto de Microbiología Básica y Aplicada, Argentina.

Contacto: merpastorini@yahoo.com.ar

\section{Mario Enrique Lozano}

Universidad Nacional de Quilmes, Departamento de Ciencia y Tecnología, Área de Virosis Emergentes y Zoonóticas, Laboratorio de Ingeniería Genética y Biología Celular y Molecular, Instituto de Microbiología Básica y Aplicada, Argentina.

Contacto: mario.lozano@unq.edu.ar

\section{Sandra Elizabeth Goñi}

Universidad Nacional de Quilmes, Departamento de Ciencia y Tecnología, Área de Virosis Emergentes y Zoonóticas, Laboratorio de Ingeniería Genética y Biología Celular y Molecular, Instituto de Microbiología Básica y Aplicada, Argentina. 
Divulgatio. Perfiles académicos de posgrado, Vol. 2, Número 5, 2018, 48-76.

Contacto: sgoni@unq.edu.ar

Recibido: marzo de 2018

Aceptado: mayo de 2018

\begin{abstract}
Resumen
Las vacunas más exitosas utilizadas en la actualidad han sido desarrolladas utilizando métodos convencionales que siguen el paradigma establecido por Pasteur hace más de un siglo, de "aislar, inactivar e inyectar" el microorganismo causante de la enfermedad y, de esta forma, imitar una infección natural. Con la llegada de la metagenómica, la selección de antígenos basada en la información genómica ha desempeñado un papel importante en el descubrimiento de nuevos inmunógenos para el diseño de vacunas. Un enfoque que ha utilizado esta estrategia ha sido denominado "vacunología inversa" y ha permitido el escrutinio del repertorio antigénico potencial de un organismo a través de su genoma, gracias a herramientas bioinformáticas predictivas. Mediante métodos in vitro de clonado molecular, las proteínas seleccionadas como antígenos son producidas a mediana escala y evaluadas en modelos animales para ensayar su capacidad de generar una respuesta inmune protectora. El objetivo principal es evaluar la capacidad de la respuesta inmune de eliminar o neutralizar al patógeno al momento de la infección. Cuanto más neutralizante es la respuesta inmune ante un antígeno específico, mayor potencial tendrá el mismo como vacuna.

En este review se resume la evolución de la vacunología desde sus comienzos en el siglo XVIII con la aparición de la vacuna de la viruela hasta el desarrollo de la vacunología inversa, haciendo especial hincapié en el desarrollo de VLPs como plataformas vacunales y su futuro en medicina preventiva.
\end{abstract}

Palabras clave: VLPs; vacunología; plataforma vacunal; proteínas recombinantes.

\title{
Abstract
}

The most successful vaccines have been developed using conventional methods that follow the paradigm established by Pasteur in the XIX century: "to isolate, inactivate and inject" the pathogen microorganism and mimic a natural infection. With the arrival of metagenomics, the selection of antigens based on genomic information has played an important role in the discovery of new immunogens for vaccine design. The main approach that has used this strategy has been called "reverse vaccinology" and allows to screen the entire potential antigenic repertoire of an organism through its genome, using predictive bioinformatic tools. Using in vitro molecular cloning methods, the protein or proteins selected as antigens may be artificially produced to evaluate their capacity of generating a protective immune response in animal models. The main aim of this approach is to evaluate the ability of the immune response to eliminate or neutralize the pathogen at the time of infection. Those antigens capable of generate a specific immune response with neutralizing activity for future natural infections are the best candidate vaccines.

This review summarizes the evolution of vaccinology since its inception in the eighteenth century with the emergence of the smallpox vaccine to the development of reverse vaccinology, with special emphasis on the development of VLPs as vaccine platforms and their future in preventive medicine.

Keywords: VLPs; vaccinology; vaccine; recombinant proteins. 
Divulgatio. Perfiles académicos de posgrado, Vol. 2, Número 5, 2018, 48-76.

\section{Vacunología: Los principios de Pasteur y el desarrollo de vacunas}

Junto a las mejoras sanitarias, el descubrimiento y uso de antibióticos, la vacunación ha constituido uno de los avances de mayor impacto en la salud humana y en el aumento de la expectativa de vida. Según la Organización Mundial de la Salud (WHO, del inglés World Health Organization), la inmunización debería ser reconocida como el principal componente del derecho a la salud humana, y su acceso debe ser una responsabilidad individual, social y gubernamental, dado que únicamente la vacunación previene unos 2,5 millones de muertes al año en todo el mundo (World Health Organisation, 2011). Sin embargo, a pesar de la existencia de esta valiosa herramienta las enfermedades infecciosas siguen siendo la principal causa de muerte en todo el mundo.

Desde el origen de la vacunología clásica o convencional en 1796, con el descubrimiento de la vacuna contra la viruela, se han producido numerosos avances tecnológicos en la lucha contra las enfermedades infecciosas. En el pasado, el desarrollo de vacunas y de agentes terapéuticos se llevó a cabo sin el conocimiento básico de la patogénesis de los agentes infecciosos. De esta forma, la vacunología clásica se ha constituido sobre el desarrollo empírico con el mínimo conocimiento de los complejos mecanismos inmunológicos por los cuales las vacunas inducen inmunidad protectora (Plotkin, 2009).

La llegada de la genómica ha cambiado radicalmente la forma en que se identifica a los candidatos vacunales. Como resultado de las revoluciones tecnológicas, se ha dado lugar a un renacimiento en el desarrollo de vacunas en el que la identificación rápida y dirigida de nuevos antígenos vacunales es posible mediante análisis genómicos, transcriptómicos y proteómicos a gran escala. Gracias al desarrollo de la Bioinformática, se han introducido nuevos métodos para el diseño y la descripción de antígenos y el análisis de la respuesta inmune generada (Rinaudo et al., 2009). Las tecnologías basadas en la genómica han revelado también nuevos factores de virulencia de diversos patógenos.

El mecanismo de acción de las vacunas depende enteramente de la activación de los componentes inmunológicos protectores del propio organismo, y las vacunas vivas atenuadas o inactivadas han sido exitosas gracias a que imitan básicamente el tipo de inmunidad protectora inducida en las personas que sobreviven a una infección natural.

Las vacunas más exitosas utilizadas en la actualidad han sido desarrolladas utilizando métodos convencionales que siguen el paradigma establecido por Pasteur hace más de un siglo, de "aislar, inactivar e inyectar" el microorganismo causante de la enfermedad y, de esta forma, imitar una infección natural (Plotkin, 2009). La estrategia para el desarrollo de estas vacunas se basó en: 1) reducir la virulencia del organismo causante de la enfermedad; 2) 
inhibir su capacidad para replicarse; 3) generar la consiguiente atenuación y/o inactivación; 4) privar a los organismos infecciosos de su patogenicidad y 5) preservar su inmunogenicidad.

Pasteur aplicó los principios detallados anteriormente a finales del siglo XIX a virus (virus de la rabia aislados de conejos), y bacterias (bacilos de ántrax inactivados por calor). Estas estrategias han sido exitosas para aquellos patógenos con antígenos invariantes que, tras una única infección, generan memoria inmunitaria en el organismo capaz de evitar re-infecciones posteriores, como por ejemplo, la viruela, la fiebre amarilla, la poliomielitis, la rabia, las paperas, el sarampión, la rubéola, la varicela, el herpes zoster, la hepatitis $A$, y encefalitis japonesa (Figura 1, izquierda) (Rappuoli, 2007). Además, también se han desarrollado vacunas inactivadas o vivas atenuadas contra algunas enfermedades infecciosas bacterianas con diferentes grados de éxito; el Bacilo Calmette-Guerin (BCG o Mycobacterium bovis vivo atenuado) es posiblemente la vacuna más utilizada en todo el mundo y actualmente la única vacuna disponible contra la tuberculosis (Parida and Kaufmann, 2010).

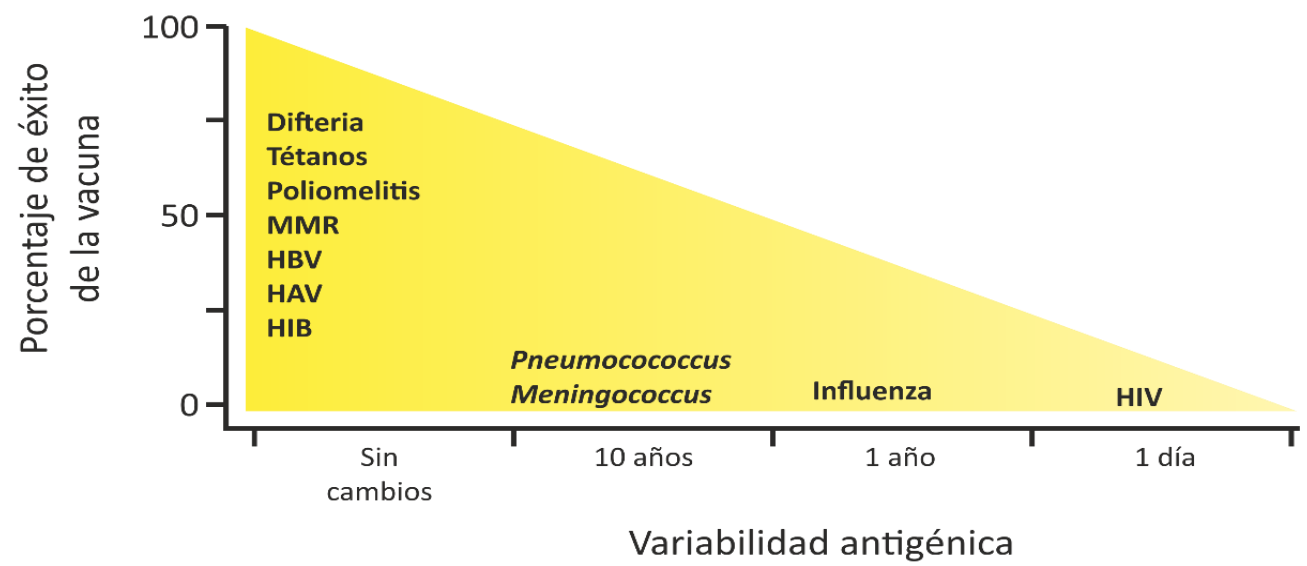

Figura 1: Éxito relativo de las vacunas en relación a la variedad antigénica del patógeno de origen.

Se observa que el éxito de la vacuna disminuye linealmente con el incremento de la capacidad del patógeno en variar sus antígenos blanco. Se muestran solo algunas vacunas a modo de ejemplo. MMR: triple viral contra sarampión, paperas y rubéola (del inglés, Measles, Mumps-Rubella); HBV: virus de la hepatitis B; HAV: virus de la hepatitis A; HIB: $H$. influenzae tipo B (modificado de (Rappuoli, 2007)).

Sin embargo, la vacunología clásica ha demostrado ser inadecuada en el desarrollo de vacunas para aquellos patógenos que son antigénicamente diversos, que no pueden ser cultivados en el laboratorio, aquellos que carecen de modelos animales adecuados de 
infección, y/o respuestas inmunitarias dependientes de células T (respuesta celular) (Figura 1, derecha).

El desarrollo de las vacunas de subunidad fue otro avance importante basado en la estrategia de Pasteur: se aislaron e inactivaron componentes esenciales del patógeno, usualmente determinantes de la virulencia, para su uso como vacunas de "subunidad". Este enfoque se utilizó por primera vez para la difteria y el tétanos, en los que la patología de la enfermedad se debió en gran medida a las toxinas producidas por el patógeno bacteriano, y las vacunas toxoideas iniciales fueron toxinas químicamente inactivadas aisladas de bacterias.

En la actualidad, las vacunas de subunidad han crecido notablemente y se ha optimizado la capacidad de generar respuestas inmunes y memoria inmunológica. A su vez, son seguras y eficaces, y se han desarrollado formulaciones multivalentes, por ejemplo, para proporcionar protección contra numerosos serotipos neumocócicos y serogrupos meningocócicos.

Por otro lado, aunque la desaparición virtual de enfermedades como la difteria, el tétanos, la tos ferina y la Haemophilus influenzae tipo B invasiva son puntos de referencia para el éxito de las vacunas, todavía quedan muchas enfermedades para las cuales las estrategias de vacunación hasta ahora no han tenido éxito. Esto se debe no sólo a la hipervariabilidad de sus antígenos sino también a una comprensión incompleta de los mecanismos de patogenicidad y a la necesidad de respuestas inmunes mediadas por células (Rappuoli, 2007) (Figura 2). Un ejemplo claro lo constituye el HIV (del inglés, human immunodeficiency virus, virus de la inmunodeficiencia humana), que al poseer epítopes hipervariables, no estimulan la inmunidad humoral adaptativa y, por lo tanto, las vacunas deben inducir inmunidad celular con bajo o nulo potencial protector en el tiempo.

Con la aplicación de nuevas técnicas recombinantes para la expresión y purificación de proteínas para vacunas de subunidad y la inactivación genética por mutagénesis dirigida, entre otras técnicas de biología molecular, se ha logrado desarrollar vacunas vivas atenuadas y vacunas de subunidad más seguras a través del diseño in silico previo. Esta tecnología también ha sentado las bases de una amplia gama de nuevas plataformas para el diseño y la administración de vacunas. Los antígenos recombinantes de una vacuna de subunidad suelen ser mejor tolerados que los patógenos vivos atenuados o inactivados o las subunidades "naturales" purificadas para vacunación. Esto se debe mayormente a que son producidos en cultivos celulares obtenidos a partir de los huéspedes que infectan naturalmente y sus proteínas presentan modificaciones postraduccionales idénticas a las presentes en los viriones infecciosos wild type. Sin embargo, una limitación es que generalmente son menos inmunogénicas $y$, a menudo, requieren la adición de un adyuvante para generar una respuesta inmune protectora (Mbow et al., 2010). 


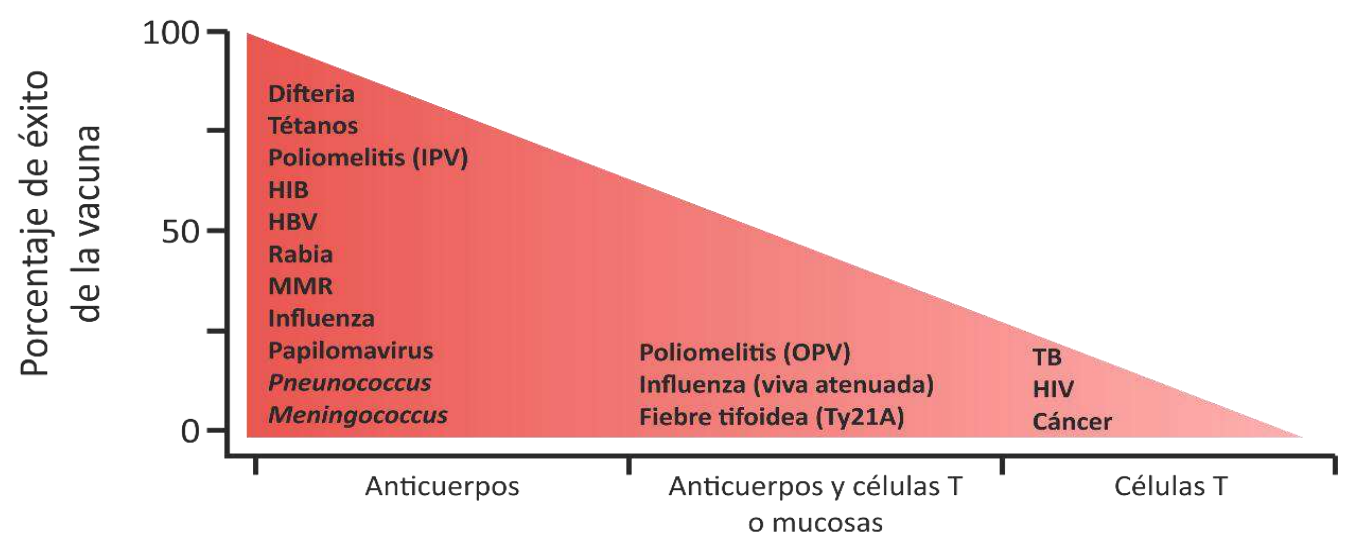

Tipo de inmunidad

Figura 2: Éxito relativo de las vacunas en uso en relación al tipo de inmunidad generada.

Se puede observar que el grado de protección decrece con la disminución en la capacidad de generar respuesta humoral. IPV: poliomavirus inactivado (del inglés, inactivated poliomavirus); OPV: poliomavirus oral (del inglés, oral poliomavirus); TB: tuberculosis (modificado de (Rappuoli, 2007)).

\section{Vacunología Inversa: Identificación de nuevos antígenos potenciales}

Con la llegada de la metagenómica, la selección de antígenos basada en el genoma ha desempeñado un papel importante en el descubrimiento de nuevos inmunógenos para el diseño de vacunas. Un enfoque que ha utilizado esta estrategia ha sido denominado "vacunología inversa" y ha permitido el escrutinio del repertorio antigénico potencial de un organismo a través de su genoma, gracias a herramientas bioinformáticas predictivas (Figura $3)$.

La vacunología inversa implica el clonado y la expresión de todas las proteínas en la secuencia del genoma de un organismo predichas de manera in silico, para ser expresadas de manera recombinante, vehiculizadas como antígeno de superficie o secretadas en forma monomérica u oligomérica para ser purificadas. Mediante métodos in vitro de clonado molecular, las proteínas son producidas a mediana escala y evaluadas en modelos animales para ensayar su capacidad de generar una respuesta inmune protectora. El objetivo principal es evaluar la capacidad de la respuesta inmune de eliminar o neutralizar al patógeno al momento de la infección. Cuanto más neutralizante es la respuesta inmune ante un antígeno específico, mayor potencial tendrá el mismo como vacuna. 


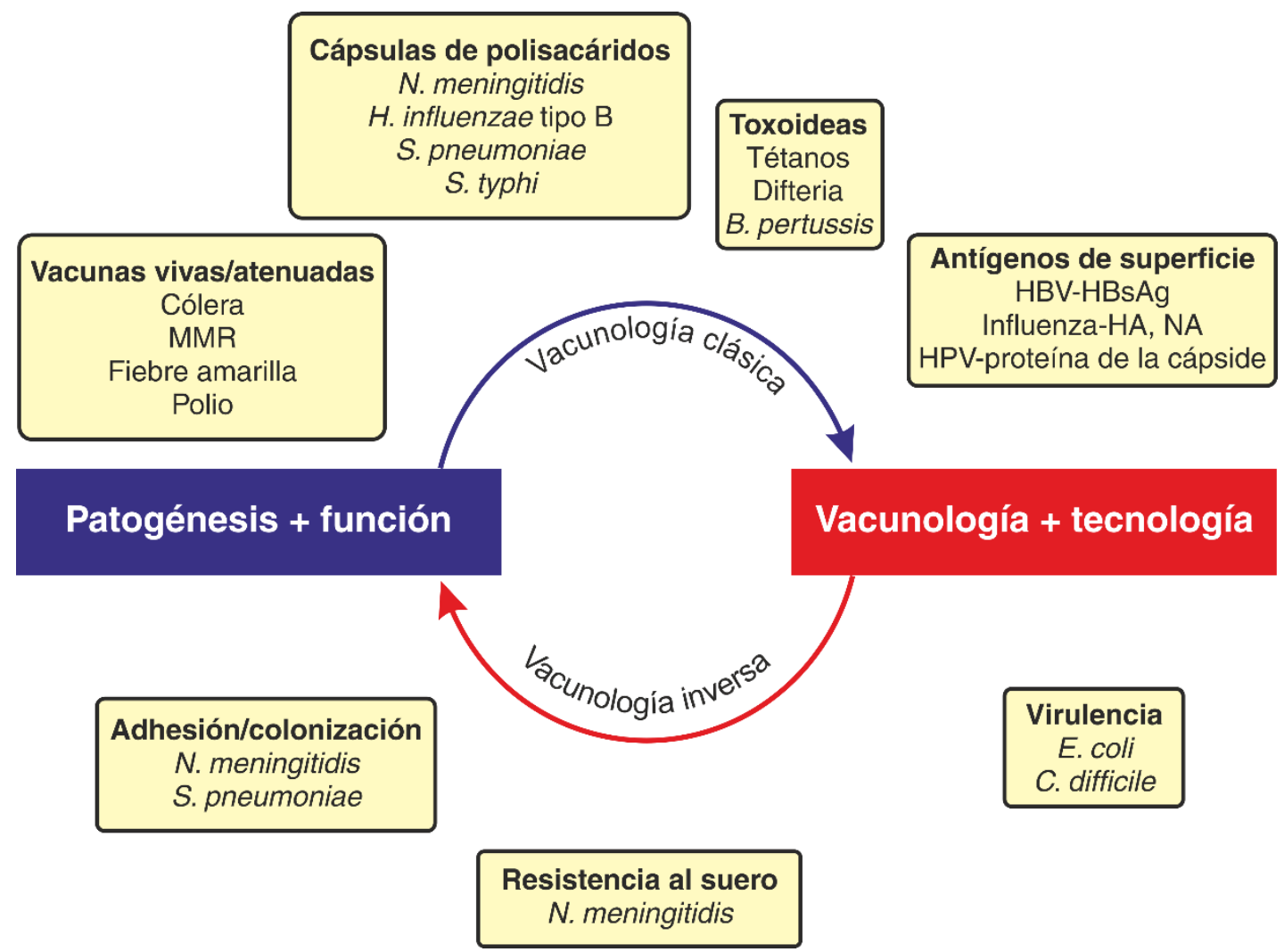

Figura 3: Interacción entre la patogénesis y el desarrollo de la vacunología clásica e inversa. MMR: triple viral (del inglés Measles-Mumps-Rubella, sarampión, paperas y rubéola) HBV-HBs-Ag: antígeno menor del virus de la hepatitis B; HA: hemaglutinina; NA: neuraminidasa; HPV: virus del papiloma humano (Ulmer et al., 2006).

Este enfoque se ha aplicado a una amplia gama de patógenos y ha proporcionado una larga lista de antígenos cuya funcionalidad era desconocida, a partir del escrutinio de sus genomas (Yinda et al., 2017). Los estudios posteriores sobre la función de cada antígeno permiten además una mayor comprensión de la biología de los patógenos. Un ejemplo es el uso de antígenos protectores implicados en la adhesión bacteriana, ya que puede haber implicaciones importantes para proporcionar inmunidad mediante la reducción de la colonización y circulación del patógeno. De hecho, los estudios funcionales de muchos antígenos protectores han revelado posteriormente que son nuevas adhesinas implicadas en la colonización del patógeno (Capecchi et al., 2005; Rosini et al., 2006).

Aunque un antígeno vacunal no necesariamente tiene que ser un factor de virulencia, centrarse en proteínas con una función crucial en la patogénesis o la supervivencia es un criterio de selección útil ya que los anticuerpos inducidos por este tipo de antígenos pueden bloquear su función y resultar en la neutralización general del patógeno. 
El primer patógeno en el cual se utilizó vacunología inversa fue Neisseria meningitidis sero grupo B (Pizza et al., 2000). Se identificaron 29 nuevos antígenos que pueden inducir una respuesta humoral bactericida contra el patógeno in vitro. Trabajos realizados a partir de tres de los antígenos principales que componen la vacuna MenB, el antígeno de unión a heparina de Neisseria, NHBA, (Neisseria heparinbinding antigen), la proteína de unión al factor $\mathrm{H}$, fHbp (factor $H$ binding protein) y la adhesina A, NadA (Neisseria adhesin A) han sido relacionados posteriormente como importantes factores de virulencia en la infección meningocócica (Capecchi et al., 2005).

Desde esta primera aplicación de la vacunología inversa se han registrado diversos avances. En 2005, Maione y colaboradores (Maione et al., 2006) aplicaron un enfoque de "vacunología inversa multi-genoma o pan-genoma" al estreptococo del grupo B para identificar antígenos del pool génico completo de la especie en lugar de un único organismo; más recientemente se ha implementado el enfoque de "vacunología inversa substractiva" para identificar antígenos presentes en cepas patogénicas no comestibles de Escherichia coli (Moriel et al., 2010).

\subsection{Diseño racional de vacunas}

Actualmente, la principal aplicación de la vacunología inversa es el diseño racional de vacunas candidatas o con potencial vacunal. Este nuevo enfoque ha reemplazado los principios obsoletos de la vacunología clásica de ensayo y error, a pesar de haber tenido éxito en el pasado.

El diseño racional sigue un enfoque escalonado (Figura 4): 1) se debe identificar un antígeno blanco, 2) seleccionar una plataforma vacunal, 3) optimizar factores para la expresión génica, 4) producir y caracterizar la vacuna, y por último 5) probar la bioseguridad, inmunogenicidad y eficacia en modelos animales (Osterhaus et al., 2010).

En el caso de la virología, los recientes avances en biología molecular y bioinformática han contribuido significativamente a la comprensión de la estructura, la replicación, la atenuación y los determinantes de la patogenicidad. Conocer estos aspectos es crucial para identificar las proteínas blanco (Osterhaus et al., 2010). 


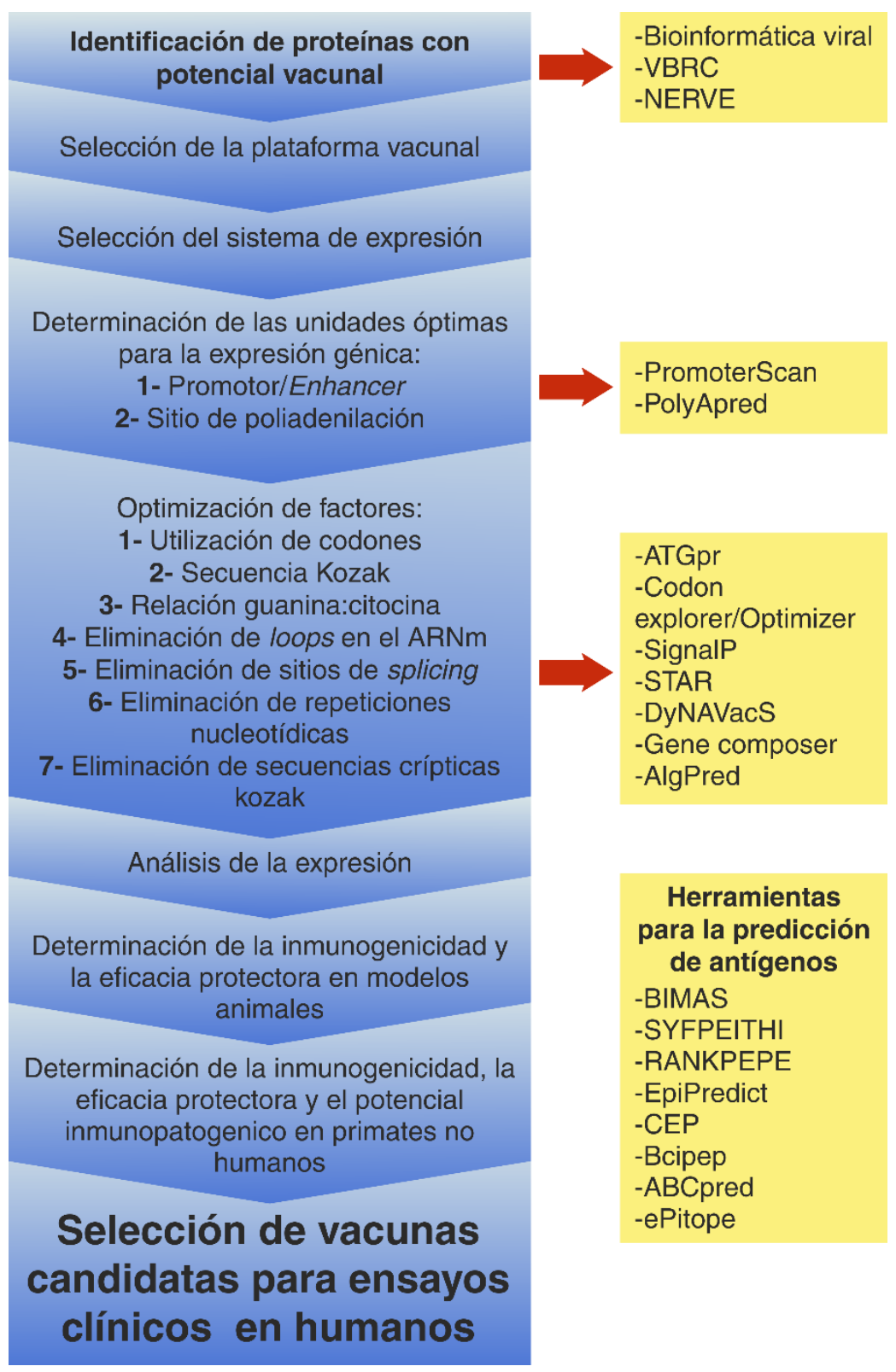

Figura 4: Diseño racional de vacunas.

El diseño racional de vacunas se basa enteramente en la predicción bioinformática; gracias a la vacunología computacional se han desarrollado herramientas para facilitar la selección del antígeno, la maximización de la expresión, la determinación de la inmunogenicidad y finalmente, la selección de las vacunas candidatas (Osterhaus et al., 2010).

En los últimos años se han desarrollado herramientas bioinformáticas, englobadas dentro de la "vacunología computacional", que facilitan el proceso de identificación antigénica de manera predictiva. La mayoría de las herramientas bioinformáticas utilizadas se centran en 
la presentación y el procesamiento de antígenos, con el objetivo de direccionar la respuesta hacia las células $\mathrm{T}$ y $\mathrm{B}$. Aunque el mapeo y la identificación de los epítopes altamente inmunogénicos en antígenos blanco es importante, varios pasos adicionales deben ser considerados al diseñar racionalmente nuevas vacunas. Los problemas comunes encontrados durante el desarrollo de vacunas incluyen el bajo rendimiento de las proteínas seleccionadas $\mathrm{y}$, por consiguiente, la baja inmunogenicidad.

\section{La vacunología estructural y el uso de partículas tipo virales (VLPs, virus- likeparticles) como plataformas vacunales}

La vacunología estructural es una disciplina emergente que tiene como objetivo identificar, diseñar y evaluar antígenos con potencial vacunal, basada en los estudios de la biología estructural, la biología computacional, la inmunología y la serología (Dormitzer et al., 2012). Sumado a esto, el desarrollo actual de la transcriptómica y la proteómica permiten escrutar el conjunto de antígenos expresados por un patógeno bajo condiciones específicas, examinando el ARN mensajero y las proteínas de un organismo, respectivamente. El análisis puede centrarse únicamente en el subconjunto de proteínas que están expuestas a la superficie (proteoma de superficie) o en el subconjunto de genes que son funcionalmente importantes para la infección (genómica funcional) (Rinaudo et al., 2009).

Asimismo, existen nuevos campos de estudio que se centran en dilucidar el conjunto de antígenos que interactúan con el sistema inmune del huésped y los mecanismos implicados en estas interacciones (inmunómica), así también como la forma en que el sistema inmunológico del huésped individual responde a una vacuna (vaccinomics o vaccinómica). Si bien cada uno de estos enfoques tiene limitaciones, todos ellos han surgido como poderosas herramientas en el desarrollo de vacunas y se vinculan directamente con la vacunología estructural.

En comparación con las vacunas del siglo XIX y principios del XX a partir de patógenos muertos, inactivados o vivos atenuados, las vacunas modernas contienen subunidades proteicas antigénicas aisladas, altamente purificadas y más seguras; sin embargo, los niveles de inmunidad protectora que suelen inducir son menores.

Un enfoque que intenta superar esta desventaja es el uso de partículas tipo virales o VLPs (del inglés Virus-likeparticles), las cuales son conjuntos de polipéptidos que presentan múltiples copias de antígenos de subunidad en ordenamientos bien organizados con orientaciones definidas que pueden imitar la repetitividad, la geometría, el tamaño e incluso la forma de la superficie natural en la que interaccionan el huésped y el patógeno. 
Estas VLPs, compuestas de antígenos virales únicos o múltiples, en algunos casos anclados en una bicapa lipídica, pueden ser generadas por proteínas estructurales de diferentes microorganismos y han servido como plataforma para la presentación de epítopes inmunogénicos: la proteína plll del fago filamentoso f1 (De La Cruz et al., 1988), el componente Ty de Saccharomy cescerevisiae (Burns et al., 1992), las proteínas de superficie o de capa del virus bluetongue (BTV, del inglés bluetongue virus) (Belyaev and Roy, 1992), el parvovirus humano B19 (Brown et al., 1994), el virus del mosaico del tabaco o (TMV, del inglés tobacco mosaic virus) (Hwang et al., 1994a) y el virus del papiloma humano (HPV, del inglés human papilloma virus) (Paavonen et al., 2017), y estos son sólo algunos ejemplos.

El uso de estas VLPs con capacidad de autoensamblarse se ha combinado eficazmente con la disciplina emergente de la vacunología estructural para lograr el máximo impacto en el diseño racional de antígenos vacunales.

\subsection{VLPs: impacto en la vacunología}

Las VLPs son asociaciones supramoleculares que no llevan ninguna información genética, no son replicativas, pueden producirse en sistemas de expresión heteróloga a gran escala e incorporan las características inmunológicas clave del virus incluyendo patrones y estructuras de superficie repetitivos con potencial para la inducción de inmunidad innata y adaptativa. Esto último tiene lugar mediante la activación de receptores de reconocimiento de patrones y receptores de células B antígeno-específico, respectivamente (Blanco, 2013).

Muchos antígenos pueden ser expuestos en la superficie de las VLPS, pudiendo estar genética o químicamente fusionados a ellas (Kim et al., 2011; Lin et al., 2014). De esta forma, estas construcciones se presentan como potentes herramientas en el campo de la inmunología y vacunología, ya que son consideradas muy eficientes como plataformas vacunales y sistemas de delivery terapéutico.

El reconocimiento de la inmunogenicidad y el potencial comercial de las VLPs ha acelerado considerablemente las investigaciones y su desarrollo. Se ha reportado que las VLPs estimulan el sistema inmune de manera completa: a) estimulan la inmunidad innata a través de los receptores tipo Toll (TLRs, del inglés Toll-likereceptors) y de los receptores reconocedores de patrones (PRRs, del inglés Pattern recognition receptors) debido a la expresión de estructuras multivalentes; b) inducción de una fuerte respuesta humoral y también de IgM en células $\mathrm{T}$ de manera independiente; c) aumento de la afinidad, el procesamiento y la presentación por las APCs (del inglés, antigen presenting cells) a través de la vía de presentación cruzada de los MHC I (del inglés, major histocompatibility complex class 
I) y MHC II (del inglés, major histocompatibility complex class II) debido a la naturaleza particulada de las VLPs (Kündig et al., 2015).

\subsubsection{Estructura de las VLPs}

Se han generado VLPs con potenciales aplicaciones a partir de una gran cantidad de virus que infectan animales y humanos (Kushnir et al., 2012). Están compuestas por una o más proteínas estructurales (o de la cápside) con propiedad de autoensamblarse en estructuras morfológicas idénticas o similares a los viriones de origen. Comparadas con los viriones completos, cuentan con la ventaja de ser bioseguras al no replicar ni infectar las células del huésped, debido a la ausencia de material genético. Además, se ha reportado que pueden ser utilizadas sin la necesidad de adyuvantes artificiales, como sí ocurre en las vacunas comerciales convencionales (Liu et al., 2012; Zeltins, 2013).

Las proteínas estructurales responsables de la generación de VLPs varían dependiendo de la biología del virus de origen: a) cápsides virales simples con una o dos proteínas estructurales principales (ej: Parvovirus, HPV, Circovirus, Calcivirus, el virus de la hepatitis E (HEV, del inglés, hepatitis E virus) y Poliomavirus); b) cápsides virales complejas, formadas por varias capas de proteínas virales, codificadas por diferentes ARNm o generadas a partir de un único polipéptido (ej: Picornavirus); c) cápsides virales con envoltura lipídica derivada de la célula huésped incluyendo espículas glicoproteicas de superficie (ej: Influenza, HIV, hepatitis C, HCV, del inglés hepatitis C virus y arenavirus) (Roy and Noad, 2009).

\subsubsection{Procesamiento de las VLPs por el sistema inmune}

Las VLPs pueden ser inoculadas de manera subcutánea o intramuscular. Su pequeño diámetro facilita la entrada en sistema linfático y drenan directamente a los nódulos locales. Una vez en el nódulo linfático, las VLPs son procesados por las células dendríticas (DCs, del inglés dendritic cells); la captura mediada por las DCs se ve aumentada por la forma y el tamaño de las VLPs, idénticas a las de los viriones infecciosos. Una vez procesadas, estimulan las células $\mathrm{T}-C D^{+}$a través de la vía del $\mathrm{MHC}$ II y la vía del MHC I, induciendo primeramente a la inmunidad innata.

\subsubsection{Inducción de la inmunidad innata}

En algunos casos, las VLP no requieren el uso de adyuvantes para lograr una estimulación inmune eficiente. Los efectos autoadjuvantes son inherentes a su tamaño 
adecuado para la captación por las DCs, su posterior procesamiento y presentación por MHC de clase II y para promover directamente la maduración y migración de DCs, esenciales para la respuesta inmune innata (Fifis et al., 2004; Gamvrellis et al., 2004). Las VLPs también pueden ser captadas y procesadas a través de la vía del MHC clase I (presentación cruzada) para la activación de células $\mathrm{T}^{-} \mathrm{CD} 8^{+}$, esenciales para la eliminación de patógenos intracelulares. La capacidad de las VLPs para dirigir DCs es una ventaja importante de las vacunas de VLPs, ya que ahora se entiende que la orientación de este tipo de células es esencial para activar las respuestas inmunes innatas y adaptativas.

Por otro lado, las VLPs que retienen sus regiones de unión al receptor son capaces de ingresar a las células a través de su receptor normal y son captadas por las APCs como antígenos exógenos para la presentación en MHC clase I. Se ha demostrado que la captación mediada por receptor ocurre en los paramyxovirus y en el HIV (Beignon et al., 2005; Zeng et al., 2002).

En el caso de la estimulación de las DCs para producir citoquinas, como el interferón$\alpha / \beta$, no requiere la replicación del virus, sino más bien una envoltura intacta de un virus inactivado (Frank et al., 2002) o la de una VLP intacta no envuelta, como en el caso del HPV (Lenz et al., 2001). En este contexto, las VLPs pueden tener ventajas muy importantes sobre los virus vivos afines para la activación inmune, porque se sabe que varios virus que se replican en las DCs bloquean la activación y maduración de la célula a través de la expresión de proteínas virales particulares (Ostrowski et al., 2005) e incluso el virus Ebola inactivado y el virus Marburg interfieren con la activación de DCs, lo que sugiere una proteína viral presente en el virus y no la VLP es la responsable de esta interferencia.

\subsubsection{Inducción de la inmunidad adaptativa}

Con el fin de inducir inmunidad adaptativa o humoral en altos títulos de anticuerpos, los antígenos blanco deben estar expuestos en la superficie de las VLPs en altas densidades. Las VLPs son comúnmente más inmunogénicas que los inmunógenos de subunidad o las proteínas recombinantes y son capaces de estimular tanto la respuesta inmune humoral como la celular. Poseen una estructura espacial que permite la correcta visualización de los epítopes conformacionales y, al imitar la estructura del virus nativo, aumentan con ello la producción de anticuerpos neutralizantes. Esto es especialmente importante para las proteínas superficiales de parásitos y virus envueltos, donde las VLP envueltas permiten que las proteínas se presenten en su estado natural como proteínas ancladas a la membrana, más que como los ectodominios en solución (Bachmann and Jennings, 2010a). 
Es por esto que las VLPs pueden ofrecer un abordaje seguro y eficaz para la inducción de anticuerpos a proteínas de superficie donde las formas solubles de las proteínas no han sido eficaces. Algunas VLPs también tienen la capacidad de presentar múltiples proteínas vacunales al sistema inmune. Por ejemplo, a pesar del éxito de la vacuna contra el virus de la hepatitis $B$ (HBV, del inglés hepatitis $B$ virus), se ha buscado optimizar su eficacia mediante la inclusión de otras dos proteínas de la envoltura en la partícula HBsAg, imitando así la envoltura auténtica de virión que contiene estas tres proteínas. Las vacunas de HBV que incluyen estas proteínas de envoltura adicionales estimulan la producción de anticuerpos de manera diferente, pero más específicamente proporcionan epítopes de células $T$ adicionales que promueven una respuesta $\alpha-\mathrm{HBsAg}$ más completa y mejoran la tasa de seroprotección superando la falta de respuesta a la vacuna HBsAg (Madalinski et al., 2001).

Otro ejemplo importante es el HIV para el cual se han hecho grandes esfuerzos para recrear la envoltura del virión en una forma que permita la inducción eficiente de anticuerpos neutralizantes. Se produjeron VLPs en forma de proteoliposomas sintéticos en perlas microesféricas sólidas con el fin de imitar el entorno de la membrana lipídica para la presentación de la glicoproteína HIV GP160 (Grundner et al., 2002), así como VLPs imitando la partícula de HIV intacto, que contiene las proteínas de la envoltura asociada con la proteína Gag (Doan et al., 2005). Esto, sumado a los avances aportados por la vacunología inversa, ha ayudado al entendimiento de que los dominios clave asociados con la entrada viral y las regiones conservadas, probablemente no experimenten variación antigénica a pesar de la presión inmunológica neutralizante. Recientemente, la investigación se ha centrado en la presentación de epítopes altamente conservados y neutralizantes de la proteína de la envoltura GP41 del HIV-1 en una conformación de pre-fusión, que sólo se expone brevemente durante la entrada viral (McGaughey et al., 2004).

Es probable que estos objetivos específicos para el desarrollo de vacunas requieran experimentación con la amplia variedad de VLPs existentes y en todos los sistemas de expresión disponibles, el uso de ensayos funcionales, tales como la unión al receptor, reactividad a anticuerpos específicos de conformación y lo más importante la inducción de neutralización cruzada de anticuerpos.

\subsection{VLPs como plataformas vacunales}

Además de ser vacunas potenciales contra los virus de los que derivan, las VLPS también pueden ser utilizadas para presentar epítopes individuales de otros organismos al sistema inmune. Esto puede realizarse mediante la fusión génica y la posterior expresión de la proteína recombinante resultante o mediante la conjugación química entre el antígeno blanco 
y la proteína estructural generadora de VLPs, ofreciendo nuevas perspectivas en el desarrollo de vacunas.

Uno de los logros más recientes del desarrollo de VLPs como plataformas vacunales es el de la vacuna contra la malaria, compuesta por la proteína circumsporozoíto de Plasmodium falciparum fusionada al antígeno de superficie de la hepatitis B con capacidad de generación de VLPs, para obtener VLPs recombinantes quiméricas (rVLPs, del inglés recombinant viruslikeparticles). Esta vacuna candidata, denominada RTS-S, ha alcanzado la fase III de ensayos clínicos e induce una protección de aproximadamente 30-50\% (Agnandji et al., 2011). A pesar de esta moderada eficacia, que puede explicarse por la baja expresión del antígeno en la superficie de las VLPS, la RTS-S es la primera vacuna que ha generado una protección significativa contra la malaria, donde otras estrategias como péptidos sintéticos y vectores virales han fallado hasta el momento.

De forma similar, se han utilizado otras plataformas para vehiculizar antígenos foráneos, usando estructuras simples conformadas por proteínas con capacidad de autoensamblarse tales como la proteína HBcore, la proteína de la envoltura del virus del mosaico de la alfalfa, la proteína L1 del HPV o el bacteriófago Qb y se ha demostrado que estimulan eficazmente respuestas inmunes específicas contra los antígenos vehiculizados (Gao et al., 2013; Jones et al., 2013; Matić et al., 2011; Spohn et al., 2010). En particular, la elección del patógeno del que derivan las proteínas estructurales para la formación de la VLP es crucial ya que influye en la inmunogenicidad global y estos estudios demuestran el gran potencial de las rVLPs ya que muchas de ellas ya han llegado a la fase de ensayo clínico (Kushnir et al., 2012).

Con el avance en el conocimiento de los virus más complejos, las rVLPs derivadas de virus envueltos ofrecen también un panorama alentador para integrar antígenos blancos presentados sobre las partículas en la envoltura, es decir, anclados en su membrana.

Otra estrategia viable para la vehiculización antigénica es el pseudotipado, donde utilizando herramientas de ingeniería genética, se anclan antígenos foráneos, decorando partículas pseudovirales. Es importante destacar que los pseudovirus, a diferencia de las VLPs, son virus completos que portan proteínas ajenas a las codificadas en su genoma aportando funciones extras al momento de infectar, que no estarán presentes en la progenie viral. Este enfoque presenta dos ventajas importantes: a) un medio para la presentación ordenada en la conformación nativa de los antígenos blanco y, b) un medio para optimizar la captación del vector por las APCs. Los núcleos retrovirales han demostrado ser adaptables para este enfoque. Se han desarrollado rVLPs basados en oncoretrovirus simples (retroVLPs, del inglés retrovirus-likeparticles), mediante el uso del retrovirus de la leucemia murina (XMRV, del inglés Xenotropic murine leukemia virus). La expresión celular de la proteína Gag, la proteína de matriz retroviral, es suficiente para generar partículas pleomórficas envueltas de 
un diámetro de 80-120 nm, que pueden ser pseudotipadas con glicoproteínas retrovirales o de otras familias virales, incluyendo el virus de la coriomeningitis linfocitaria (LCMV, del inglés lymphocytic choriomeningitis virus), el virus de la necrosis del bazo (SNV, del inglés spleen necrosis virus), el virus de la estomatitis vesicular (VSV, del inglés vesicular stomatitis virus), el $\mathrm{HCV}$, el virus de la fiebre amarilla (YFV, del inglés yellow fever virus), el virus West Nile (WNV, del inglés West Nile virus), el virus Influenza, el HIV y el citomegalovirus (CMV) (Bellier and Klatzmann, 2013; Dalba et al., 2007), sin perjudicar su funcionalidad.

Curiosamente, las retroVLPs pueden adaptarse mediante tecnología recombinante para incorporar alta densidad de antígenos en su superficie, lo que constituye una optimización significativa que mejora su inmunogenicidad.

\subsection{Sistemas de expresión de VLPs}

La selección del vector de expresión es uno de los factores más importantes en la generación de VLPs. Ha sido reportada la producción exitosa de 174 VLPs diferentes, un $28 \%$ en bacterias, $20 \%$ en células de levadura y $28 \%$ en células de insectos, un $15 \%$ en animales y un $9 \%$ en plantas. Estos dos últimos sistemas se aplican para el caso de VLPs con propiedades particulares (Zeltins, 2013).

\subsubsection{Sistemas bacterianos}

Los sistemas bacterianos comerciales de uso convencional incluyen los vectores de expresión y las cepas de Escherichiacoli aptas para expresar altas cantidades de VLPs no envueltas. En comparación con otros sistemas, la producción en bacterias es altamente eficiente en cuanto a cantidad (Joshi et al., 2013). Sin embargo, a pesar de las ventajas cuantitativas, muchas veces los sistemas bacterianos no son aptos para la producción de VLPs con potencial vacunal debido a varios factores: a) incapacidad de generar proteínas recombinantes con modificaciones postraduccionales similares a las de células de mamífero; b) fallo en la formación de puentes disulfuro; c) cambios en la solubilidad de la proteína; y d) adición de lipopolisacaridos (LPS, del inglés lipopolysaccharide) o endotoxinas a las proteínas recombinantes.

Sin embargo, las proteínas de la cubierta (CPs, del inglés coat proteins) de algunos virus pueden ser producidas eficientemente en cuerpos de inclusión insolubles, purificadas bajo condiciones desnaturalizantes, renaturalizadas y autoensambladas, como se ha reportado para el caso de las VLPs del parvovirus B19, y en varios virus de plantas (Hwang et al., 1994b, 1994a). Un cambio sutil en las condiciones de cultivo, como la baja temperatura, puede 
resolver el problema de los cuerpos de inclusión e inducir la formación de VLPs solubles, como se logró para el virus $Y$ de la papa (PYV, del inglés potato $Y$ virus) (Kalnciema et al., 2012). Algunos factores, como los marcadores de resistencia de los plásmidos de expresión o la composición de los medios de cultivo también pueden alterar el ensamblaje de las VLPs. Otra estrategia aplicada para incrementar los niveles de expresión y solubilidad implica utilizar diferentes sistemas de proteínas de fusión, como por ejemplo la glutatión-S-tranferasa (GST) o proteínas de fusión como L1 de HPV (Middelberg et al., 2011).

También pueden utilizarse otros procariotas para generar VLPS, como Lactobacillus (Zeltins, 2013). El ensamblaje intracelular de VLPs de L1 del HPV subtipo 16 ha sido reportado en Lactobacillus casei, una cepa de expresión inducible mediante lactosa (Kushnir et al., 2012). Además, mediante la producción de VLPs de L1 en Lactobacillus se han desarrollado nuevas vacunas de profilaxis vía mucosas (Aires et al., 2006).

Otro sistema de expresión alternativo a $E$. coli es Pseudomonas fluorescens ( $P$. fluorescens). Esta bacteria es utilizada por su comodidad en el manejo de los cultivos, la alta producción de proteína soluble y la posibilidad de cultivar a gran escala. Sin embargo, existen diferencias entre $P$. fluorescens y $E$. coli como el tamaño del genoma y metabolismo que pueden influenciar la generación de proteínas recombinantes. La proteína de la cápside de un bromovirus de plantas, el virus del moteado clorótico de caupí (CCMV, del inglés cowpea chlorotic mottle virus), ha sido expresada de forma soluble en $P$. fluorescens y ha sido capaz de ensamblarse en VLPs de forma autónoma in vivo, siendo estas VLPs de estructura similar a la de los viriones naturales (Phelps et al., 2007).

\subsubsection{Sistemas de levadura}

Los sistemas de expresión eucariota son una alternativa importante a la expresión en bacterias debido a la ausencia de endotoxinas bacterianas para el desarrollo de vacunas. De hecho, la primera vacuna basada en VLPs aprobada contra el HBV fue desarrollada en levaduras (Burns et al., 1992). Lo más importante de este sistema es que las VLPs no se autoensamblan durante el cultivo celular, sino que en Picchia pastoris se completa el ensamblado durante el proceso de purificación posterior de las proteínas (Lünsdorf et al., 2011).

El sistema de $P$. pastoris ha sido utilizado para expresar las glicoproteínas de premembrana y envoltura del virus del Dengue tipo 2 (DENV-2) (Liu et al., 2010). Otro de los avances en el sistema de expresión en levaduras, fue el desarrollo de métodos de expresión multigénicos. Se han expresado tres genes estructurales de rotavirus a partir de un único vector de expresión que permitió la generación de VLPs trilaminadas en Saccharomy 
cescerevisiae (Rodríguez-Limas et al., 2011). Sin embargo, la multimerización de las proteínas en VLPs derivadas de virus envueltos no ha sido exitosa en el caso de las Gag-VLPs del HIV2, lo que sugiere que este sistema de expresión carece de los factores esenciales como huésped para generar VLPs envueltas.

En resumen, si bien este sistema de expresión tiene la ventaja de poseer modificaciones postraduccionales similares a las de células de mamífero y no aportan endotoxinas características de los procariotas para el desarrollo de plataformas vacunales, la construcción de los vectores de expresión es aún dificultosa y los patrones de glicosilación son erráticos comparados con los de las células de mamíferos, siendo únicamente útil para la generación de VLPs no envueltas.

\subsubsection{Células de insecto}

Otro sistema utilizado para producir VLPs es el de baculovirus en células de insecto debido a las ventajas de rápido crecimiento, posibilidad de cultivos a gran escala, las modificaciones postraduccionales similares a las de las células de mamíferos y posibilidad de generar VLPs envueltas y no envueltas. Existen en el mercado varias vacunas basadas en VLPs producidas en células de insecto, como Cervarix ${ }^{\circledR}$, la vacuna contra el HPV y otras basadas en VLPs envueltas están en la etapa de ensayos clínicos (Roy and Noad, 2009). La principal limitación de este tipo de sistema, son las eventuales contaminaciones con partículas proteicas de los propios baculovirus, lo que sugiere el desarrollo de mejores métodos de purificación. Se ha documentado la expresión exitosa de cuatro genes del virus de la influenza humana H3N2 en este sistema de expresión y que las VLPs generadas indujeron protección contra H3N2 en ratones desafiados (Galarza et al., 2005). Estos resultados sugieren que se podría desarrollar una vacuna basada en VLPs contra el virus de la influenza H9N2 y otros subtipos de influenza aviar. Las VLPs no infecciosas de SAV (del inglés salmonid alphavirus) también fueron generadas usando baculovirus recombinantes que expresaban la proteína de la cápsula y dos glicoproteínas inmunodominantes E1 y E2 en células de insecto (Metz et al., 2011).

\subsubsection{Células de mamíferos}

Por más de dos décadas se han desarrollado líneas celulares de mamíferos como fuente de proteínas terapéuticas comerciales para aplicaciones clínicas debido a su habilidad de plegar, ensamblar y modificar las proteínas de manera postraduccional de manera correcta (Wurm, 2004). Las desventajas de este modelo incluyen los costos de producción y 
mantenimiento de las líneas celulares y la bioseguridad. En un principio, se utilizaron líneas celulares de mamíferos para producir VLPs del virus de la influenza como plataformas vacunales, incluso se desarrollaron líneas estables que expresan proteínas estructurales de influenza que permitieron generar VLPs híbridas conteniendo la proteína de matriz y las glicoproteínas de superficie de los tipos H3N2 y H5N1 (Wu et al., 2010).

Otros ejemplos incluyen la producción de VLPs a partir del virus de la enfermedad de Newcastle (NDV, del inglés Newcastle disease virus) en células ELL (East Lansing Line) y de VLPs de circovirus (PCV, del inglés porcine circovirus) y parvovirus (PVV, del inglés porcine parvovirus) porcinos, y de los virus Lassa (LASV, del inglés Lassa virus), Marburg (MARV, del inglés Marburg virus) y Ébola (EBOV, del inglés Ebola virus), en células HEK 293T (del inglés human embryo kidney) (Swenson et al., 2005). También se ha documentado la producción de VLPs del bacteriófago T7 en células HepG2 (línea celular de hepatocitos de cáncer de hígado), de HIV-1-VLPs en células COS-7 (CV1-Origin-SV40) y Vero (línea celular epitelial de riñón de Cercopithecus aethiops) y de HBV-VLPs en células $\mathrm{CHO}$ (del inglés chinese hámster ovary) (Assateerawatt et al., 1993).

\subsubsection{Sistemas de expresión en plantas}

Los sistemas de expresión en plantas se utilizan para expresar productos génicos específicos. Se han utilizado plantas recombinantes de tabaco, tubérculos de papa, entre otras, para la generación de antígenos vacunales. Los antígenos expresados en plantas tienen la particularidad de formar puentes disulfuro y oligomerizar de manera correcta para formar VLPs y son capaces de expresar VLPs envueltas y no envueltas, tanto multiméricas como quiméricas. La alta expresión de VLPs en plantas es simple y rápida si se utiliza el sistema de replicón de ARN de TMV o el sistema de replicón de ADN del virus del poroto amarillo enano (BYMV, del inglés bean yellow mosaic virus) (Chen and Lai, 2013).

\section{VLPs derivadas del virus Junín (JUNV-VLPs) en la UNQ}

En nuestro laboratorio hemos generado VLPs arenavirales utilizando la capacidad de brotación de la proteína de matriz $Z$ del virus Junín (Borio et al., 2012) transfectando de manera transitoria células HEK 293T (Figura 5). A partir de estos resultados y basándonos en la interacción entre la proteína $Z$ y el resto de las proteínas del virión, hemos diseñado y desarrollado una plataforma en forma de vector plasmídico que permita la expresión heteróloga de antígenos foráneos anclados a la membrana de las VLPs. 


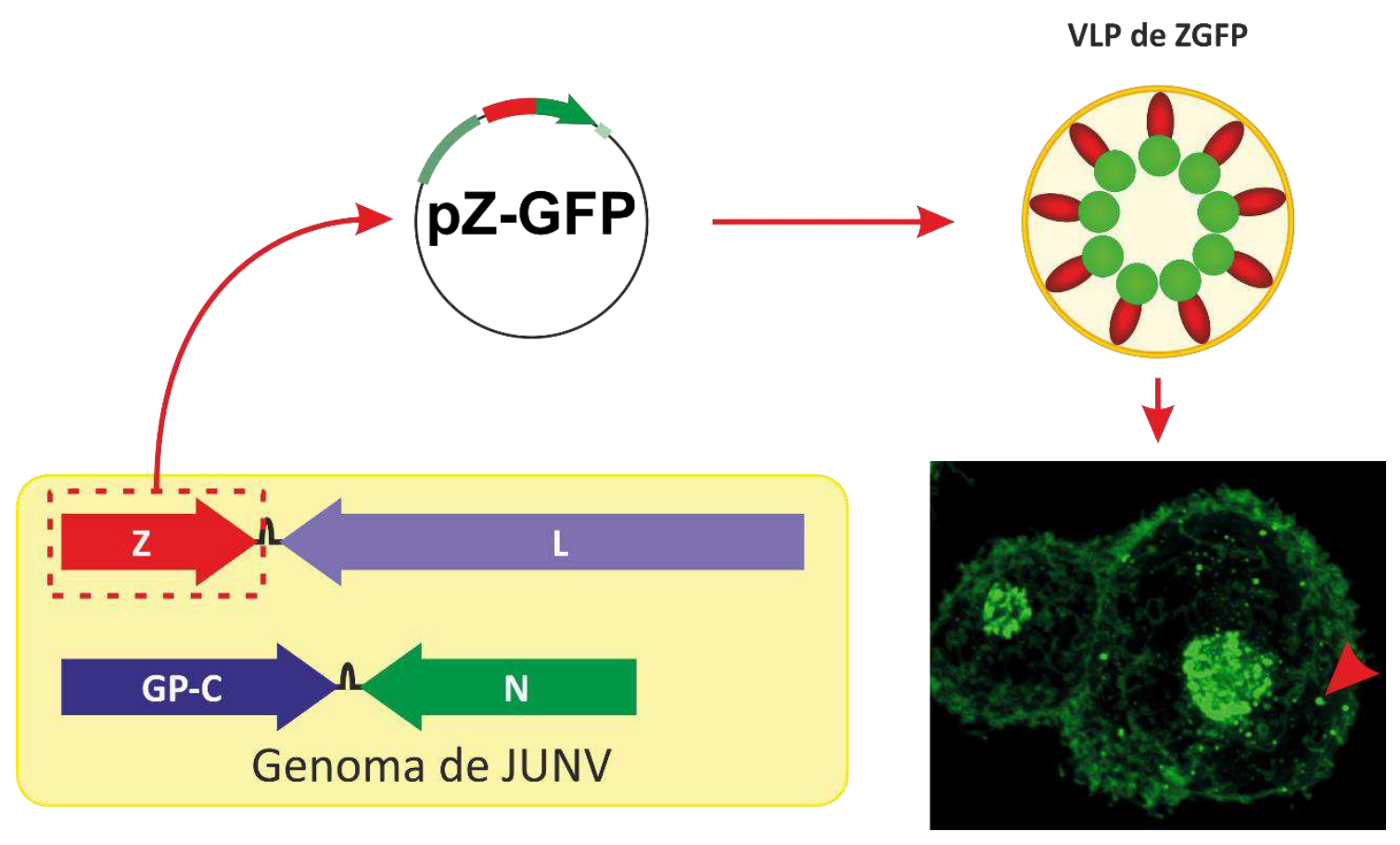

Figura 5: Esquema de la obtención de JUNV-VLPs fluorescentes en el AVEZ-LIGBCM de la UNQ.

Mediante herramientas de biología molecular se construyó un vector plasmídico pZGFP que codifica una fusión proteica entre la proteína de matriz $Z$ de JUNV y GFP; luego de la transfección transiente de células HEK 293T se pudo observar la correcta expresión de la proteína recombinante Z-GFP y la generación de JUNV-VLPs fluorescentes mediante microscopía confocal (Borio et al., 2012).

El diseño incluyó los elementos genómicos mínimos de anclaje y direccionamiento a membrana del complejo de las glicoproteínas de JUNV capaces de interaccionar además con Z que garanticen su incorporación en las VLPs (De Ganzó, 2017). Este vector fue denominado pResAg, por plásmido presentador de antígenos.

Si bien hemos sido capaces de clonar diferentes antígenos virales en pResAg (el ectodominio de la hemaglutinina del virus del sarampión y la proteína NS1 del virus de Saint Louis) y hemos comprobado su correcta expresión con anticuerpos específicos (De Ganzó, 2017), la validación del modelo se está llevando a cabo con la proteína indicadora GFP debido a sus obvias ventajas fluorescentes y por sus propiedades de conferir estabilidad a las proteínas heterólogas que incluyen su secuencia. Actualmente, se está ensayando la coexpresión de pResAg y la proteína Z con el fin de generar VLPs fluorescentes debido a la inserción de GFP en sus membranas. Estos ensayos, junto a la inoculación de animales de 
laboratorio y la evaluación de la respuesta inmune generada in vivo, nos permitirá evaluar la capacidad de pResAg de ser utilizado como plataforma vacunal a futuro.

\section{Limitaciones de aplicación de las vacunas basadas en VLPs}

Como se describió anteriormente, las VLPs se pueden considerar como sistemas de presentación antigénica que inducen respuestas inmunitarias potentes y amplias contra diversos antígenos blanco, teniendo, además, ventajas de bioseguridad e inmunogenicidad frente a los enfoques tradicionales. Existe una clara tendencia hacia el uso de VLPs como plataformas para el desarrollo de muchas vacunas profilácticas. Sin embargo, existen consideraciones técnicas y prácticas que pueden limitar la aplicación de vacunas de VLPs. En primer lugar, debido a su naturaleza particulada, las vacunas basadas en VLPs sólo pueden ser eficaces contra epítopos de células B o T específicas que están altamente conservadas. Debido a que muchos patógenos experimentan variación antigénica en respuesta a las presiones inmunitarias del huésped durante el curso de la infección, las VLPs, por lo tanto, no inducirían respuestas inmunitarias de larga duración contra antígenos variantes. En segundo lugar, teniendo en cuenta el estrés inmunológico o la baja velocidad de biodegradabilidad, no debe ignorarse la posible toxicidad de las VLP en el organismo. Los estudios de toxicidad deben diseñarse para maximizar las posibilidades de evaluación los efectos tóxicos resultantes de la acción farmacológica primaria o secundaria de las vacunas de VLPS (Bachmann and Jennings, 2010b). Por último, pero no menos importante, los anticuerpos preexistentes o maternos contra las VLPs pueden afectar adversamente la inmunogenicidad, lo que resultaría en una falla en la vacunación (Chackerian, 2007).

\section{Conclusiones y discusión}

La vacunología inversa ha acelerado la identificación de nuevos epítopes antigénicos en agentes infecciosos, tumores y alérgenos, y ha impulsado el diseño racional de vacunas basadas en epítopes aislados de su entorno natural (Chiang et al., 2015; Lin et al., 2014). Sin embargo, la conversión de estos antígenos en inmunógenos eficientes continúa siendo un desafío. En este aspecto, las VLPs se presentan como una alternativa prometedora ya que pueden ser desarrolladas con las más avanzadas herramientas de ingeniería genética, biología molecular y biología estructural. Las VLPs de virus antropozoonóticos formadas por elementos estructurales de los viriones maduros han recibido considerable atención durante las últimas dos décadas (Crossey et al., 2015; Espinosa et al., 2017; Fan et al., 2018; Schickli et al., 2015; Zhang et al., 2016). De hecho, los datos de campo sugieren que las VLPs son 
más efectivas que muchos otros tipos de vacunas de subunidad contra diferentes patologías infecciosas. En un futuro cercano, la industria biofarmacéutica entrará en una nueva era con el desarrollo de las VLPs como una poderosa herramienta en el campo de la vacunología. Recientemente se han comenzado a desarrollar vacunas terapéuticas basadas en VLPs con el objetivo de inducir respuesta humoral contra moléculas que están involucradas en patologías o procesos crónicos (Chackerian, 2007). Cuatro de estas vacunas humanas basadas en VLPs han sido evaluadas clínicamente y se ha logrado un objetivo primordial: la reducción de la presión sanguínea en pacientes hipertensos. Asimismo, para facilitar las pruebas clínicas preliminares, se han desarrollado nuevos programas de estudio no clínicos (Bachmann and Jennings, 2010b). Las vacunas preventivas y las terapéuticas también se pueden aplicar en el campo veterinario para aliviar el sufrimiento de animales que padecen enfermedades crónicas y no pueden ser sacrificados considerando el bienestar animal (Melegari et al., 2018).

Otra de las funciones primordiales de la vacunología inversa es la optimización de vacunas preexistentes o el mejoramiento de la respuesta inmune protectora inducida por vacunas de VLPs desarrolladas a través de esta tecnología. Este es el caso de la vacuna contra el virus de la hepatitis B HBcAg-VLPs donde la adición de residuos en el extremo carboxilo de la proteína recombinante generadora de VLPs ha conferido una mayor estabilidad al conjunto y se ha optimizado su rendimiento (Schumacher et al., 2018).

Asimismo, en los últimos años se han suscitado epidemias virales extremadamente peligrosas por la agresividad de las infecciones y sus altas tasas de mortalidad, como es el caso de las epidemias de EBOV y DENV. Ante estas emergencias sanitarias y la inexistencia de vacunas preventivas o terapéuticas, se han desarrollado modelos vacunales mediante técnicas de vacunología reversa basadas en VLPs con excelentes resultados (Hoenen and Groseth (eds.), 2017; Lázaro-Frías et al., 2018; Metz et al., 2018; Ren et al., 2018; Reynard and Mateo, 2017; Tripathi et al., 2015).

En conclusión, se han reportado numerosos casos exitosos y se siguen describiendo nuevas aplicaciones a las VLPs, siendo el uso de VLPs como plataformas vacunales, el campo más prometedor en la medicina preventiva durante el siglo XXI.

\section{Información de los autores}

Los doctores Agustín De Ganzó, Cristina Borio, Mario Lozano y Sandra Goñi son docentes investigadores del Departamento de Ciencia y Tecnología de la UNQ y son miembros del Área de Virosis Emergentes y Zoonóticas del Laboratorio de Ingeniería Genética y Biología Celular y Molecular (AVEZ-LIGBCM). Mercedes Pastorini es Diplomada en Ciencia y Tecnología de la UNQ y es estudiante avanzada de la carrera de Licenciatura en 
Divulgatio. Perfiles académicos de posgrado, Vol. 2, Número 5, 2018, 48-76.

Biotecnología; en la actualidad se encuentra realizando su seminario de investigación en la validación del modelo de pResAg y en la evaluación de la respuesta inmune celular generada por las VLPs de Z-GFP en AVEZ-LIGBCM.

\section{Agradecimientos}

AVEZ-LIGBCM forma parte del Instituto de Microbiología Básica y Aplicada (IMBA) de la UNQ y cuenta con subsidios del Fondo para la Investigación Científica y Tecnológica de la Agencia Nacional de Promoción Científica y Tecnológica (FONCyT-ANPCyT), de la UNQ y del Consejo Nacional de Investigaciones Científicas y Técnicas (CONICET).

\section{Referencias bibliográficas}

Agnandji, S.T., Lell, B., Solmeheim Soulanoudjingar, S., Fernandes, J. F. (2011). First Results of Phase 3 Trial of RTS,S/AS01 Malaria Vaccine in African Children. N. Engl. J. Med. 362, 1863-1875. https://doi.org/10.1056/NEJMoa1102287

Aires, K.A., Cianciarullo, A.M., Carneiro, M., Villa, L.L., Boccardo, E., Pérez-martinez, G., Perez-arellano, I., Leonor, M., Oliveira, S., Ho, P.L., Carneiro, S.M., Pe, G., (2006). Production of Human Papillomavirus Type 16 L1 Virus-Like Particles by Recombinant Lactobacillus casei Cells Production of Human Papillomavirus Type 16 L1 Virus-Like Particles by Recombinant Lactobacillus casei Cells. Appl. Environ. Microbiol. 72, 745-52. https://doi.org/10.1128/AEM.72.1.745

Assateerawatt, A., Tanphaichitr, V.S., Suvatte, V., Yodthong, S. (1993). Immunogenicity and efficacy of a recombinant DNA hepatitis B vaccine, Gen HevacB Pasteur in high risk neonates, school children and healthy adults. Asian Pac. J. Allergy Immunol. 11, 85-91.

Bachmann, M.F., Jennings, G.T., 2010a. Vaccine delivery: a matter of size, geometry, kinetics and molecular patterns. Nat. Rev. Immunol. 10, 787-96. https://doi.org/10.1038/nri2868

Bachmann, M.F., Jennings, G.T., 2010b. Vaccine delivery: a matter of size, geometry, kinetics and molecular patterns. Nat. Rev. Immunol. 10, 787-96. https://doi.org/10.1038/nri2868

Beignon, A.S., McKenna, K., Skoberne, M., Manches, O., Da Silva, I., Kavanagh, D.G., Larsson, M., Gorelick, R.J., Lifson, J.D., Bhardwaj, N. (2005). Endocytosis of HIV-1 activates plasmacytoid dendritic cells via Toll-like receptor-viral RNA interactions. J. Clin. Invest. 115, 3265-3275. https://doi.org/10.1172/JCl26032

Bellier, B., Klatzmann, D. (2013). Virus-like particle-based vaccines against hepatitis C virus infection. Expert Rev. Vaccines 12, 143-54. https://doi.org/10.1586/erv.13.10

Belyaev, A.S., Roy, P. (1992). Presentation of hepatitis B virus preS2 epitope on bluetongue virus core-like particles. Virology 190, 840-844.

Blanco, E. (2013). Structure and Physics of Viruses, Subcellular Biochemistry. Springer Netherlands, Dordrecht. https://doi.org/10.1007/978-94-007-6552-8 
Borio, C. S., Bilen, M.F., Argüelles, M. H., Goñi, S.E., Iserte, J. a, Glikmann, G., Lozano, M. E., (2012). Antigen vehiculization particles based on the $Z$ protein of Junin virus. BMC Biotechnol. 12, 80. https://doi.org/10.1186/1472-6750-12-80

Brown, C. S., Welling-Wester, S., Feijlbrief, M., Van Lent, J. W., Spaan, W. J. (1994). Chimeric parvovirus B19 capsids for the presentation of foreign epitopes. Virology. https://doi.org/10.1006/viro.1994.1059

Burns, N. R., Saibil, H.R., White, N. S., Pardon, J.F., Timmins, P. A., Richardson, S. M., Richards, B. M., Adams, S.E., Kingsman, S.M., Kingsman, A.J., (1992). Symmetry, flexibility and permeability in the structure of yeast retrotransposon virus-like particles. EMBO J. 11, $1155-64$.

Capecchi, B., Adu-Bobie, J., Di Marcello, F., Ciucchi, L., Masignani, V., Taddei, A., Rappuoli, R., Pizza, M., Aric??, B. (2005). Neisseria meningitidis NadA is a new invasin which promotes bacterial adhesion to and penetration into human epithelial cells. Mol. Microbiol. 55, 687-698. https://doi.org/10.1111/j.1365-2958.2004.04423.x

Chackerian, B., (2007). Virus-like particles: flexible platforms for vaccine development. Expert Rev. Vaccines 6, 381-90. https://doi.org/10.1586/14760584.6.3.381

Chen, Q., Lai, H., (2013). Plant-derived virus-like particles as vaccines. Hum. Vaccines Immunother. 9, 26-49. https://doi.org/10.4161/hv.22218

Chiang, M.-H., Sung, W.-C., Lien, S.-P., Chen, Y.-Z., Lo, A.F., Huang, J.-H., Kuo, S.-C., Chong, P. (2015). Identification of novel vaccine candidates against Acinetobacter baumannii using reverse vaccinology. Hum. Vaccines Immunother. 11, 1065-1073. https://doi.org/10.1080/21645515.2015.1010910

Crossey, E., Frietze, K., Narum, D.L., Peabody, D.S., Chackerian, B. (2015). Identification of an Immunogenic Mimic of a Conserved Epitope on the Plasmodium falciparum Blood Stage Antigen AMA1 Using Virus-Like Particle (VLP) Peptide Display. PLoS ONE 10. https://doi.org/10.1371/journal.pone.0132560

Dalba, C., Bellier, B., Kasahara, N., Klatzmann, D. (2007). Replication-competent vectors and empty virus-like particles: new retroviral vector designs for cancer gene therapy or vaccines. Mol. Ther. J. Am. Soc. Gene Ther. 15, 457-466. https://doi.org/10.1038/sj.mt.6300054

De Ganzó, (2017). Desarrollo de una plataforma de presentación y vehiculización de antígenos basada en VLPs derivadas del virus Junín. UNQ, Bernal, Buenos Aires, Argentina.

De La Cruz, V.F., Lal, A. A., McCutchan, T.F., (1988). Immunogenicity and epitope mapping of foreign sequences via genetically engineered filamentous phage. J. Biol. Chem. 263, 43184322.

Doan, L. X., Li, M., Chen, C., Yao, Q., (2005). Virus-like particles as HIV-1 vaccines. Rev. Med. Virol. 15, 75-88. https://doi.org/10.1002/rmv.449

Dormitzer, P.R., Grandi, G., Rappuoli, R. (2012). Structural vaccinology starts to deliver. Nat. Rev. Microbiol. 10, 807-13. https://doi.org/10.1038/nrmicro2893

Espinosa, D., Mendy, J., Manayani, D., Vang, L., Wang, C., Richard, T., Guenther, B., Aruri, J., Avanzini, J., Garduno, F., Farness, P., Gurwith, M., Smith, J., Harris, E., Alexander, J. (2017). 
Passive Transfer of Immune Sera Induced by a Zika Virus-Like Particle Vaccine Protects AG129 Mice Against Lethal Zika Virus Challenge. EBioMedicine 27, 61-70. https://doi.org/10.1016/j.ebiom.2017.12.010

Fan, Y.-C., Chen, J.-M., Lin, J.-W., Chen, Y.-Y., Wu, G.-H., Su, K.-H., Chiou, M.-T., Wu, S.-R., Yin, J.-H., Liao, J.-W., Chang, G.-J.J., Chiou, S.-S. (2018). Genotype I of Japanese Encephalitis Virus Virus-like Particles Elicit Sterilizing Immunity against Genotype I and III Viral Challenge in Swine. Sci. Rep. 8, 7481. https://doi.org/10.1038/s41598-018-25596-1

Fifis, T., Gamvrellis, A., Crimeen-Irwin, B., Pietersz, G.A., Li, J., Mottram, P.L., McKenzie, I.F.C., Plebanski, M., (2004). Size-Dependent Immunogenicity: Therapeutic and Protective Properties of Nano-Vaccines against Tumors. J. Immunol. 173, 3148-3154. https://doi.org/10.4049/jimmunol.173.5.3148

Frank, I., Piatak, M., Stoessel, H., Romani, N., Bonnyay, D., Lifson, J.D., Pope, M. (2002). Infectious and whole inactivated simian immunodeficiency viruses interact similarly with primate dendritic cells (DCs): differential intracellular fate of virions in mature and immature DCs. J. Virol. 76, 2936-51. https://doi.org/10.1128/JVI.76.6.2936

Galarza, J.M., Latham, T., Cupo, A., (2005). Protection against a Lethal Influenza Virus Challenge 18, 244-251.

Gamvrellis, A., Leong, D., Hanley, J.C., Xiang, S.D., Mottram, P., Plebanski, M. (2004). Vaccines that facilitate antigen entry into dendritic cells. Immunol. Cell Biol. 82, 506-516. https://doi.org/10.1111/j.0818-9641.2004.01271.x

Gao, X., Wang, W. J., Li, Y.F., Zhang, S.G., Duan, Y.Q., Xing, L., Zhao, Z.P., Zhang, P.R., Li, Z.W., Li, R.S., Wang, X., Yang, P.H., (2013). Enhanced Influenza VLP vaccines comprising matrix-2 ectodomain and nucleoprotein epitopes protects mice from lethal challenge. Antiviral Res. 98, 4-11. https://doi.org/10.1016/j.antiviral.2013.01.010

Grundner, C., Mirzabekov, T., Sodroski, J., Wyatt, R., (2002). Solid-phase proteoliposomes containing human immunodeficiency virus envelope glycoproteins. J. Virol. 76, 3511-21. https://doi.org/10.1128/JVI.76.7.3511

Hoenen, T., Groseth (eds.), A., (2017). Ebolaviruses: Methods and Protocols, 1st ed, Methods in Molecular Biology 1628. EE.UU: Humana Press.

Hwang, D. J., Roberts, I. M., Wilson, T. M., (1994a). Expression of tobacco mosaic virus coat protein and assembly of pseudovirus particles in Escherichia coli. Proc. Natl. Acad. Sci. U. S. A. 91, 9067-9071.

Hwang, D.J., Roberts, I.M., Wilson, T.M., (1994b). Assembly of tobacco mosaic virus and TMV-like pseudovirus particles in Escherichia coli. Arch. Virol. Suppl. 9, 543-558.

Jones, R.M., Chichester, J.A., Mett, Vadim, Jaje, J., Tottey, S., Manceva, S., Casta, L.J., Gibbs, S.K., Musiychuk, K., Shamloul, M., Norikane, J., Mett, Valentina, Streatfield, S.J., Van De Vegte-Bolmer, M., Roeffen, W., Sauerwein, R.W., Yusibov, V. (2013). A plant-produced Pfs25 VLP malaria vaccine candidate induces persistent transmission blocking antibodies against plasmodium falciparum in immunized mice. PLoS ONE 8. https://doi.org/10.1371/journal.pone.0079538 
Joshi, H., Lewis, K., Singharoy, A., Ortoleva, P.J. (2013). Epitope engineering and molecular metrics of immunogenicity: A computational approach to VLP-based vaccine design. Vaccine 31, 4841-4847. https://doi.org/10.1016/j.vaccine.2013.07.075

Kalnciema, I., Skrastina, D., Ose, V., Pumpens, P., Zeltins, A. (2012). Potato virus y-like particles as a new carrier for the presentation of foreign protein stretches. Mol. Biotechnol. 52, 129-139. https://doi.org/10.1007/s12033-011-9480-9

Kim, D., Martinez-Sobrido, L., Choi, C., Petroff, N., García-Sastre, A., Niewiesk, S., Carsillo, T., (2011). Induction of type I interferon secretion through recombinant Newcastle disease virus expressing measles virus hemagglutinin stimulates antibody secretion in the presence of maternal antibodies. J. Virol. 85, 200-7. https://doi.org/10.1128/JVI.01624-10

Kündig, T.M., Klimek, L., Schendzielorz, P., Renner, W.A., Senti, G., Bachmann, M.F. (2015). Is The Allergen Really Needed in Allergy Immunotherapy? Curr. Treat. Options Allergy 2, $72-$ 82. https://doi.org/10.1007/s40521-014-0038-5

Kushnir, N., Streatfield, S.J., Yusibov, V., (2012). Virus-like particles as a highly efficient vaccine platform: Diversity of targets and production systems and advances in clinical development. Vaccine 31, 58-83. https://doi.org/10.1016/j.vaccine.2012.10.083

Lázaro-Frías, A., Gómez-Medina, S., Sánchez-Sampedro, L., Ljungberg, K., Ustav, M., Liljeström, P., Muñoz-Fontela, C., Esteban, M., García-Arriaza, J., (2018). Distinct Immunogenicity and Efficacy of Poxvirus-Based Vaccine Candidates against Ebola Virus Expressing GP and VP40 Proteins. J. Virol. 92, e00363-18. https://doi.org/10.1128/JVI.0036318

Lenz, P., Day, P.M., Pang, Y.Y., Frye, S.A., Jensen, P.N., Lowy, D.R., Schiller, J.T. (2001). Papillomavirus-like particles induce acute activation of dendritic cells. J Immunol 166, 53465355. https://doi.org/10.4049/jimmunol.166.9.5346

Lin, Y.-L., Hu, Y.-C., Liang, C.-C., Lin, S.-Y., Liang, Y.-C., Yuan, H.-P., Chiang, B.-L., (2014). Enterovirus-71 Virus-Like Particles Induce the Activation and Maturation of Human MonocyteDerived Dendritic Cells through TLR4 Signaling. PloS One 9, e111496. https://doi.org/10.1371/journal.pone.0111496

Liu, F., Ge, S., Li, L., Wu, X., Liu, Z., Wang, Z. (2012). Virus-like particles: Potential veterinary vaccine immunogens. Res. Vet. Sci. 93, 553-559. https://doi.org/10.1016/j.rvsc.2011.10.018

Liu, W., Jiang, H., Zhou, J., Yang, X., Tang, Y., Fang, D., Jiang, L. (2010). Recombinant dengue virus-like particles from Pichia pastoris: Efficient production and immunological properties. Virus Genes 40, 53-59. https://doi.org/10.1007/s11262-009-0418-2

Lünsdorf, H., Gurramkonda, C., Adnan, A., Khanna, N., Rinas, U. (2011). Virus-like particle production with yeast: ultrastructural and immunocytochemical insights into Pichia pastoris producing high levels of the hepatitis B surface antigen. Microb. Cell Factories 10, 48. https://doi.org/10.1186/1475-2859-10-48

Madalinski, K., Sylvan, S.P.E., Hellstr??m, U., Mikolajewicz, J., Zembrzuska-Sadkowska, E., Piontek, E. (2001). Antibody responses to preS components after immunization of children with low doses of BioHepB. Vaccine 20, 92-97. https://doi.org/10.1016/S0264-410X(01)00312-7

Maione, D., Margarit, I., Rinaudo, C.D., Masignani, V., Scarselli, M., Tettelin, H., Brettoni, C., lacobini, E.T., Agostino, N.D., Miorin, L., Buccato, S., Mariani, M., Nogarotto, R., Dei, V.N., 
Vegni, F., Fraser, C., Teti, G., Madoff, L.C., Paoletti, L.C., Rappuoli, R., Kasper, D.L., Telford, J.L., Grandi, G. (2006). Identification of a Universal Group B Streptococcus Vaccine by Multiple Genome Screen 309, 148-150.

Matić, S., Rinaldi, R., Masenga, V., Noris, E. (2011). Efficient production of chimeric Human papillomavirus $16 \mathrm{~L} 1$ protein bearing the M2e influenza epitope in Nicotiana benthamiana plants. BMC Biotechnol. 11, 106. https://doi.org/10.1186/1472-6750-11-106

Mbow, M.L., De Gregorio, E., Valiante, N.M., Rappuoli, R., (2010). New adjuvants for human vaccines. Curr. Opin. Immunol. 22, 411-416. https://doi.org/10.1016/j.coi.2010.04.004

McGaughey, G.B., Barbato, G., Bianchi, E., Freidinger, R.M., Garsky, V.M., Hurni, W.M., Joyce, J.G., Liang, X., Miller, M.D., Pessi, A., Shiver, J.W., Bogusky, M.J., (2004). Progress towards the development of a HIV-1 gp41-directed vaccine. Curr. HIV Res. 2, 193-204.

Melegari, I., Marsilio, F., Di Profio, F., Sarchese, V., Massirio, I., Palombieri, A., D’Angelo, A.R., Lanave, G., Diakoudi, G., Cavalli, A., Martella, V., Di Martino, B. (2018). Seroprevalence of sapovirus in dogs using baculovirus-expressed virus-like particles. Virus Res. 251, 1-5. https://doi.org/10.1016/j.virusres.2018.04.014

Metz, S.W., Feenstra, F., Villoing, S., van Hulten, M.C., van Lent, J.W., Koumans, J., Vlak, J.M., Pijlman, G.P. (2011). Low temperature-dependent salmonid alphavirus glycoprotein processing and recombinant virus-like particle formation. PLoS ONE 6, 1-10. https://doi.org/10.1371/journal.pone.0025816

Metz, S.W., Thomas, A., White, L., Stoops, M., Corten, M., Hannemann, H., de Silva, A. M., (2018). Dengue virus-like particles mimic the antigenic properties of the infectious dengue virus envelope. Virol. J. 15. https://doi.org/10.1186/s12985-018-0970-2

Middelberg, A. P.J., Rivera-Hernandez, T., Wibowo, N., Lua, L.H.L., Fan, Y., Magor, G., Chang, C., Chuan, Y.P., Good, M.F., Batzloff, M.R. (2011). A microbial platform for rapid and low-cost virus-like particle and capsomere vaccines. Vaccine 29, 7154-7162. https://doi.org/10.1016/j.vaccine.2011.05.075

Moriel, D.G., Bertoldi, I., Spagnuolo, A., Marchi, S., Rosini, R., Nesta, B., Pastorello, I., Corea, V.A.M., Torricelli, G., Cartocci, E., Savino, S., Scarselli, M., Dobrindt, U., Hacker, J., Tettelin, H., Tallon, L.J., Sullivan, S., Wieler, L.H., Ewers, C., Pickard, D., Dougan, G., Fontana, M.R., Rappuoli, R., Pizza, M., Serino, L. (2010). Identification of protective and broadly conserved vaccine antigens from the genome of extraintestinal pathogenic Escherichia coli. Proc. Natl. Acad. Sci. U. S. A. 107, 9072-7. https://doi.org/10.1073/pnas.0915077107

Osterhaus, A.D.M.E., Koraka, P., Martina, B.E.E. (2010). Bioinformatics in new generation flavivirus vaccines. J. Biomed. Biotechnol. 2010. https://doi.org/10.1155/2010/864029

Ostrowski, M., Vermeulen, M., Zabal, O., Geffner, J.R., Sadir, a M., Lopez, O.J. (2005). Impairment of thymus-dependent responses by murine dendritic cells infected with foot-andmouth disease virus. J Immunol 175, 3971-3979. https://doi.org/175/6/3971 [pii]

Paavonen, J., Jenkins, D., Bosch, F.X., Naud, P., Salmerón, J., Wheeler, C.M., Chow, S.-N., Apter, D.L., Kitchener, H.C., Castellsague, X., de Carvalho, N.S., Skinner, S.R., Harper, D.M., Hedrick, J.A., Jaisamrarn, U., Limson, G.A.M., Dionne, M., Quint, W., Spiessens, B., Peeters, P., Struyf, F., Wieting, S.L., Lehtinen, M.O., Dubin, G. (2017). Efficacy of a prophylactic adjuvanted bivalent L1 virus-like-particle vaccine against infection with human papillomavirus 
types 16 and 18 in young women: an interim analysis of a phase III double-blind, randomised controlled trial. The Lancet 369, 2161-2170. https://doi.org/10.1016/S0140-6736(07)60946-5

Parida, S.K., Kaufmann, S.H.E. (2010). Novel tuberculosis vaccines on the horizon. Curr. Opin. Immunol. 22, 374-384. https://doi.org/10.1016/j.coi.2010.04.006

Phelps, J.P., Dao, P., Jin, H., Rasochova, L. (2007). Expression and self-assembly of cowpea chlorotic mottle virus-like particles in Pseudomonas fluorescens. J. Biotechnol. 128, 290-296. https://doi.org/10.1016/j.jbiotec.2006.10.005

Pizza, M., Scarlato, V., Masignani, V., Giuliani, M.M., Aricò, B., Comanducci, M., Jennings, G.T., Baldi, L., Bartolini, E., Capecchi, B., Galeotti, C.L., Luzzi, E., Manetti, R., Marchetti, E., Mora, M., Nuti, S., Ratti, G., Santini, L., Savino, S., Scarselli, M., Storni, E., Zuo, P., Broeker, M., Hundt, E., Knapp, B., Blair, E., Mason, T., Tettelin, H., Hood, D.W., Jeffries, A.C., Saunders, N.J., Granoff, D.M., Venter, J.C., Moxon, E.R., Grandi, G., Rappuoli, R. (2000). Identification of Vaccine Candidates Against Serogroup B Meningococcus by Whole-Genome Sequencing. Science 287, 1816-1820. https://doi.org/10.1126/science.287.5459.1816

Plotkin, S. A. (2009). Vaccines: The fourth century. Clin. Vaccine Immunol. 16, 1709-1719. https://doi.org/10.1128/CVI.00290-09

Rappuoli, R. (2007). Bridging the knowledge gaps in vaccine design. Nat. Biotechnol. 25, 1361-6. https://doi.org/10.1038/nbt1207-1361

Ren, S., Wei, Q., Cai, L., Yang, X., Xing, C., Tan, F., Leavenworth, J.W., Liang, S., Liu, W., (2018). Alphavirus Replicon DNA Vectors Expressing Ebola GP and VP40 Antigens Induce Humoral and Cellular Immune Responses in Mice. Front. Microbiol. 8. https://doi.org/10.3389/fmicb.2017.02662

Reynard, O., Mateo, M. (2017). Modeling Ebolavirus Budding with Virus Like Particles, in: Ebolaviruses, Methods in Molecular Biology. Humana Press, New York, NY, pp. 109-117. https://doi.org/10.1007/978-1-4939-7116-9_8

Rinaudo, C. D., Telford, J. L., Rappuoli, R., Seib, K. L., (2009). Vaccinology in the genome era. J. Clin. Invest. 119, 2515-2525. https://doi.org/10.1172/JCI38330

Rodríguez-Limas, W. a, Tyo, K.E.J., Nielsen, J., Ramírez, O.T., Palomares, L. a. (2011). Molecular and process design for rotavirus-like particle production in Saccharomyces cerevisiae. Microb. Cell Factories 10, 33. https://doi.org/10.1186/1475-2859-10-33

Rosini, R., Rinaudo, C.D., Soriani, M., Lauer, P., Mora, M., Maione, D., Taddei, A., Santi, I., Ghezzo, C., Brettoni, C., Buccato, S., Margarit, I., Grandi, G., Telford, J. L. (2006). Identification of novel genomic islands coding for antigenic pilus-like structures in Streptococcus agalactiae. Mol. Microbiol. 61, 126-141. https://doi.org/10.1111/j.13652958.2006.05225.x

Roy, P., Noad, R. (2009). Virus-like particles as a vaccine delivery system: myths and facts. Adv Exp Med Biol 655, 145-158. https://doi.org/10.1007/978-1-4419-1132-2_11

Schickli, J. H., Whitacre, D.C., Tang, R. S., Kaur, J., Lawlor, H., Peters, C. J., Jones, J. E., Peterson, D. L., McCarthy, M. P., Van Nest, G., Milich, D. R. (2015). Palivizumab epitopedisplaying virus-like particles protect rodents from RSV challenge. J. Clin. Invest. 125, 16371647. https://doi.org/10.1172/JCl78450 
Schumacher, J., Bacic, T., Staritzbichler, R., Daneschdar, M., Klamp, T., Arnold, P., Jägle, S., Türeci, Ö., Markl, J., Sahin, U. (2018). Enhanced stability of a chimeric hepatitis B core antigen virus-like-particle (HBcAg-VLP) by a C-terminal linker-hexahistidine-peptide. J. Nanobiotechnology 16. https://doi.org/10.1186/s12951-018-0363-0

Spohn, G., Jennings, G. T., Martina, B. E., Keller, I., Beck, M., Pumpens, P., Osterhaus, A. D., Bachmann, M. F. (2010). A VLP-based vaccine targeting domain III of the West Nile virus $E$ protein protects from lethal infection in mice. Virol. J. 7, 146. https://doi.org/10.1186/1743422X-7-146

Swenson, D. L., Warfield, K. L., Negley, D. L., Schmaljohn, A., Aman, M. J., Bavari, S. (2005). Virus-like particles exhibit potential as a pan-filovirus vaccine for both Ebola and Marburg viral infections. Vaccine 23, 3033-3042. https://doi.org/10.1016/j.vaccine.2004.11.070

Tripathi, L., Mani, S., Raut, R., Poddar, A., Tyagi, P., Arora, U., de Silva, A., Swaminathan, S., Khanna, N. (2015). Pichia pastoris-expressed dengue 3 envelope-based virus-like particles elicit predominantly domain III-focused high titer neutralizing antibodies. Front. Microbiol. 6. https://doi.org/10.3389/fmicb.2015.01005

Ulmer, J.B., Valley, U., Rappuoli, R. (2006). Vaccine manufacturing: challenges and solutions. Nat. Biotechnol. 24, 1377-1383. https://doi.org/10.1038/nbt1261

World Health Organisation (2011). Global Vaccine Action Plan. Vaccine 1-147. https://doi.org/10.1016/j.vaccine.2013.02.015

Wu, C. Y., Yeh, Y. C., Yang, Y. C., Chou, C., Liu, M. T., Wu, H. S., Chan, J. T., Hsiao, P. W. (2010). Mammalian expression of virus-like particles for advanced mimicry of authentic influenza virus. PLoS ONE 5. https://doi.org/10.1371/journal.pone.0009784

Wurm, F. M. (2004). Production of recombinant protein therapeutics in cultivated mammalian cells. Nat Biotechnol 22, 1393-1398. https://doi.org/10.1038/nbt1026

Yinda, C. K., Conceição-Neto, N., Zeller, M., Heylen, E., Maes, P., Ghogomu, S. M., Van Ranst, M., Matthijnssens, J. (2017). Novel highly divergent sapoviruses detected by metagenomics analysis in straw-colored fruit bats in Cameroon. Emerg. Microbes Infect. 6, e38. https://doi.org/10.1038/emi.2017.20

Zeltins, A. (2013). Construction and characterization of virus-like particles: A review. Mol. Biotechnol. 53, 92-107. https://doi.org/10.1007/s12033-012-9598-4

Zeng, J., Fournier, P., Schirrmacher, V. (2002). Stimulation of human natural interferon-?? response via paramyxovirus hemagglutinin lectin-cell interaction. J. Mol. Med. 80, 443-451. https://doi.org/10.1007/s00109-002-0339-1

Zhang, Y., Wang, Z., Zhan, Y., Gong, Q., Yu, W., Deng, Z., Wang, A., Yang, Y., Wang, N. (2016). Generation of <Emphasis Type="Italic">E. coli</Emphasis>-derived virus-like particles of porcine circovirus type 2 and their use in an indirect IgG enzyme-linked immunosorbent assay. Arch. Virol. 161, 1485-1491. https://doi.org/10.1007/s00705-016-2816-9 